\title{
Converging on Business-IT Alignment Best Practices: Lessons Learned from a Dutch Cross-Governmental Partnership
}

\author{
Roberto Santana Tapia \\ Department of Computer Science,University of Twente,P.O. Box 217, 7500 AE \\ Enschede, The Netherlands, r.santanatapia@utwente.nl
}

\begin{abstract}
An empirical study that explores business-IT alignment processes in a Dutch cross-governmental partnership is summarized in this paper. The aim of the study was to identify processes that contribute to improve such alignment. This study represents a continuation of previous validation efforts that helped us to confirm the business-IT alignment process areas that should ultimately be included in the ICoNOs MM - a maturity model to assess operational business-IT alignment in networked organizations. Evidence was sought for the alignment of business and IT through the use of information systems to support the requirements of the organization in a specific project. The results of this study in the public sector also are relevant to the private sector where (i) business-IT alignment plays an increasingly valuable role, and (ii) the characteristics of collaborative networked organizations are present.
\end{abstract}

\section{Keywords}

Operational alignment, collaborative networked organizations, case study research, IT-enabled joined-up government

\section{Introduction}

Aligning IT with the business remains one of the top priorities for both business practitioners and researchers. Within the broad scope of literature on alignment, a number of authors have stressed the importance of assess business-IT alignment (B-ITa) in order to plan B-ITa improvement actions (e.g. de Koning \& van der Marck, 2002; Duffy, 2001; Luftman, 2003). In support of this, these authors have developed maturity models (MMs). MMs describe the development of a specific domain over time. Based on maturity assessments, organizations know the extent to which processes in a domain are predictable. That is, organizations can be aware of whether a specific area is sufficiently refined and documented so that the activities in such area now have the potential to achieve its desired outcomes. Notwithstanding the effective application of such models in single enterprises, to the best of our knowledge there is no MM that specifically addresses the processes needed for achieving alignment between business and IT in collaborative networked organizations (CNOs). In our research, we are developing a MM to assess B-ITa in CNOs: the ICoNOs MM (IT-enabled Collaborative Networked Organizations Maturity Model). We believe that achieving B-ITa in CNOs is more complex than in single enterprises because in such settings, B-ITa is driven by goals of different independent organizations.

In previous work (Santana Tapia, 2006; Santana Tapia, Daneva, van Eck, 2007; Santana Tapia, Daneva, van Eck, Castro Cárdenas, van Oene, 2008a; Santana Tapia, Daneva, van Eck, Wieringa, 2008b; Santana Tapia, van Eck, Daneva, 2008c), we have reported on our motivation for developing the ICoNOs MM, on how we began to validate the model, and on the MM itself. This paper is an extension of previous work (Santana Tapia \& van Oene, 2008). It presents a case study conducted in a CNO among the province of Overijssel, the municipalities of Zwolle and Enschede, the water board district Regge \& Dinkel and Royal Grolsch N.V. in The Netherlands. We used this case study to empirically identify whether the B-ITa processes included in the ICoNOs MM are present in a real-life CNO. When analyzing the results of the 
case study, we recognized that the findings could also be presented in the form of best practices that can be used by CNOs when striving for B-ITa. The term 'best practices' requires some explanation. Best practices, in this paper, are validated processes that stand for effective ways to achieve a specific objective (in our case, to achieve B-ITa). Thus, B-ITa best practices are B-ITa processes that have been justified on the basis of evidence provided by verifiable observations (e.g. by a case study) and, therefore, can be presented as general guidelines. Besides, B-ITa processes are groups of practices in a domain which, when implemented collectively, satisfy goals considered important for making an improvement in that domain (e.g., a process area in the IS architecture domain is 'IS portfolio management').

In the remainder of this section we first briefly present the ICoNOs MM. The rest of this paper is organized as follows: Section 2 outlines our definitions. Section 3 describes the research approach. Then Section 4 shows the B-ITa best practices. Finally, Section 5 concludes the paper.

\subsection{The ICoNOs MM}

The ICoNOs MM is a two dimensional framework (see Figure 1). These dimensions represent the maturity levels and the domains to which these levels apply. The ICoNOs MM has five levels of maturity: level 1 incomplete, level 2 isolated, level 3 standardized, level 4 quantitatively managed, and level 5 optimized; and includes four domains: partnering structure, IS architecture, process architecture and coordination (Santana Tapia et al., 2008b).

\begin{tabular}{|l|l|l|l|l|}
\cline { 2 - 5 } \multicolumn{2}{c|}{} & \multicolumn{2}{c|}{ PARTNERING STRUCTURE } & \multicolumn{2}{c|}{ IS ARCHITECTURE } \\
\hline 5 & \multicolumn{2}{|l|}{} & $\begin{array}{l}\text { Inter-organizational IS arch. optimization } \\
\text { Risk analysis and mitigation }\end{array}$ & $\begin{array}{l}\text { IOAO } \\
\text { RAM }\end{array}$ \\
\hline 4 & Metric-based roles exploration & MRE & Quantitative IS portfolio management & QPM \\
\hline 3 & Governance structure and compliance & GSC & $\begin{array}{l}\text { I requirements management } \\
\text { IS capabilities definition } \\
\text { IS portfolio management }\end{array}$ & $\begin{array}{l}\text { ISRM } \\
\text { ISCD } \\
\text { ISPM }\end{array}$ \\
\hline 2 & $\begin{array}{l}\text { Business model definition } \\
\text { Service level agreements definition }\end{array}$ & BMD & Current IS architecture description & CSA \\
\hline 1 & & & & \\
\hline
\end{tabular}

\begin{tabular}{|c|c|c|c|c|}
\hline & \multicolumn{2}{|l|}{ PROCESS ARCHITECTURE } & \multicolumn{2}{|l|}{ COORDINATION } \\
\hline 5 & $\begin{array}{l}\text { Inter-organizational process optimization } \\
\text { Causal analysis and resolution }\end{array}$ & $\begin{array}{l}\text { IOPO } \\
\text { CAR }\end{array}$ & & \\
\hline 4 & $\begin{array}{l}\text { Organizational process performance } \\
\text { Event logs formal consistency }\end{array}$ & $\begin{array}{l}\text { OPP } \\
\text { EFC }\end{array}$ & Quantitative coordination relation analysis & QRA \\
\hline 3 & $\begin{array}{l}\text { Organizational process focus planning } \\
\text { Target process architecture formulation }\end{array}$ & $\begin{array}{l}\text { PFP } \\
\text { TPA }\end{array}$ & $\begin{array}{l}\text { Standardization } \\
\text { Communication-oriented coordination }\end{array}$ & $\begin{array}{l}\text { STD } \\
\text { COC }\end{array}$ \\
\hline 2 & Current process architecture description & CPD & $\begin{array}{l}\text { Informal communication adjustment } \\
\text { Direct supervision }\end{array}$ & $\begin{array}{l}\text { InCA } \\
\text { DTS }\end{array}$ \\
\hline 1 & & & & \\
\hline
\end{tabular}

Figure 1: The ICoNOs MM

The cells of the ICoNOs MM contain B-ITa process areas. Because of space constraints, we do not define each of these process areas in this paper. For a detailed definition of these process areas, please refer to our previous work (Santana Tapia et al., 2008b). The case study presented in this paper has been useful to identify such process areas in a real-life CNO. This serves as empirical evidence for their inclusion in the ICoNOs MM. We make an explicit note that, when finalizing the development of the ICoNOs MM, we have changed the position of some of the process areas presented in Santana Tapia \& van Oene (2008) and Santana Tapia et al. (2008b). We found that some of the process areas are strongly related to each other. We then decided to re-arrange de position of them, so that some of the original process areas are now goals of, or practices in, another process area. For example, the "inter-organizational policies definition" and the "roles and responsibilities specification" process areas in level three of the partnering 
structure domain (Santana Tapia et al., 2008b) are now included in the "governance structure and compliance" - GSC - process area.

\section{Definitional foundations}

In this section, we outline our definitions and assumptions concerning B-ITa in CNOs. This helps to clarify our research context serving as theoretical basis for the rest of the paper.

\subsection{Business-IT Alignment}

For the purpose of our research, we define B-ITa as the process to make IT services support the requirements of the business, whether such services are individually or collaboratively offered. We do not consider alignment as a steady state but as a process that needs to be performed continuously. By 'IT services' we mean services offered by computerized information systems. By the 'requirements of the business' we mean the systems requirements derived from analyzing the goal(s), the processes and the relationships in the CNO. We will focus on operational B-ITa, which consists of aligning the operational activities of IT systems and people to each other so that optimal IT support for business requirements is achieved. This contrasts with strategic BITa, where business and IT goals and policies are decided without fixing operational details.

\subsection{Collaborative Networked Organizations}

We define a CNO to be any "mix-and-match" network of profit-and-loss responsible organizational units, or of independent organizations, connected by IT, that work together to jointly accomplish tasks, reach common goals and serve customers over a period of time. Our interest is in IT-enabled CNOs, i.e., collaborations that are made possible by IT where the participants interoperate with each other by means of information systems. We believe that IT makes competition and collaboration possible, forcing organizations to focus on what they can do well and facilitating collaboration between organizations with complementary competencies.

In a public sector context, such organizations are government agencies focused on improving quality of services to citizens and on increasing cost-effectiveness of their service delivery processes. In our research, a CNO involving government agencies is termed 'cross-governmental partnership' (CGP). In a CGP, government agencies are independent from each other in the sense that each has its own public mission to fulfill in settings where they have some autonomy for budget allocation and service-delivery process definition. However, with the public mission also come (i) laws that must be conformed to and (ii) requirements such as cost-effectiveness and accountability. A government agency improves its operations if it improves the way it satisfies these criteria and, in doing so, it has a responsibility distinct from that of the other partners in the CGP. In this kind of partnerships, profit is not relevant and loss consists of not fulfilling or overspending its public mission. Therefore, a CGP is a network of government agencies responsible to fulfill a shared public mission, connected by IT, which work together over a period of time to provide services to citizens.

\section{Research Approach}

The case study research design involved multiple sources of data collected in a structured way. This situation suggests that construct validity must be addressed, and that we can generalize results to valid statements (Yin, 2003). Case study research was used because of the need to analyze complex phenomena in depth and the significant nature of the data that had to be collected (Benbasat, Goldstein, Mead, 1987; Yin, 2003). The objective of the case study presented in this paper was to identify whether the process areas included in the ICoNOs MM were present in the investigated CGP. We claim that the B-ITa process areas of the ICoNOs MM are the required processes to implement for a $\mathrm{CNO}$ to make improvements in the B-ITa domains. 
If the process areas reveal themselves as important in the case results, then we have an empirical ground for their inclusion in our MM. The research question addressed with this case was:

What are the B-ITa process areas performed by a CNO for improving its B-ITa?

This question led to the formulation of the next hypothesis: If a CNO strives to improve B-ITa, then it is possible to identify, in such a CNO, the process areas included in the ICoNOs MM.

\subsection{Case Study Context and Site}

People who want to build, re-build, or re-use a house, factory, or barn, in The Netherlands, can often need to apply for licenses and permits regarding residency, spatial planning, and the environment. Each of these licenses and permits has their own set of criteria, procedures, administrative desks, waiting periods, fees, and staff. For both citizens and companies, this is a complex and time consuming process that costs both applicants and the government a great deal of money. The Ministry for Housing, Spatial Planning and Environmental Management (VROM - initials in Dutch) wants to gather the different licenses together within the environmental permit (omgevingsvergunning). All aspects can then be requested from a single point and follow a single paid procedure to obtain a decision even if such a decision needs the collaboration of different organizations.

The environmental permit project is part of a set of measures that the Dutch government has initiated to substantially reduce administrative charges for citizens and businesses. The Enviromental Licensing (General Provisions) Bill - WABO for its initials in Dutch, forces the different public entities to cooperate with each other in a different way. This cooperation is possible only if it is supported by a correct provision of information. The environmental permit is part of the modernization plan for VROM legislation, in which the ministry is reducing and improving its rules and regulations. The project includes a development of an implementation plan with pilot projects and advice. The CGP we studied is one of these pilot projects. It is a networked organization among the province of Overijssel, the municipalities of Zwolle and Enschede, the water board district Regge \& Dinkel and Royal Grolsch N.V. (hereinafter referred to as Overijssel CGP), working in the WABO-ICT project. The aim of this project was testing the practical feasibility of the national online all-in-one service for environmental permits (LVO - initials in Dutch), steering the project on the IT services to support the business processes.

\subsection{Data Collection and Analysis Techniques}

Four types of data sources were used: (i) professionals from the case study site, (ii) meetings, (iii) documents related to WABO, LVO, the WABO-ICT project, and past projects, and (iv) illustrative materials (e.g. newsletters and videos). This combination of sources permitted triangulation of the data to increase the strength of the findings. The data collection techniques used with the professionals and the meetings were semi-structured interviews and observation, respectively. The interviews were conducted with 8 persons on a one-to-one basis. It can be argued that interview data is often biased by impression management and retrospective sensemaking. However, we mitigate such a bias by interviewing different and highly knowledgeable professionals who view the Overijssel CGP from diverse perspectives. The professionals included people from the different collaborating government agencies and diverse functional areas. Table 1 classifies the interviewees based on their expertise (B-ITa domain) and the organization they are affiliated with.

The duration of each interview was approximately 1 hour. The interviews were taped. This was done with the consent of each interviewee. When interviewing, we were primarily interested in identifying whether a process area was or was not performed in the Overijssel CGP (see the research question presented above). The interviews were theory-driven interviews (Pawson, 1996). We started each interview by presenting the overall definitional foundations and context of our research to each interviewee. The goal was to make the interviewee understand our research context and concepts (B-ITa domains and process areas in CNO settings). With such an 
understanding, the interviewees had the opportunity to explain and clarify their own thinking. In this context, the interviewee provided more meaningful answers to our questions, leading to new questions that were useful to clarify our own ideas. For example, when looking for evidence supporting the performance of the 'roles and responsibilities specification' - RRS - process area, we started asking: Was the definition of the partnering structure necessary to efficiently collaborate? We got as answer explanations about the organizational structure of the Overijssel CGP and the relationships among the participants at functional level. As a result, specific follow up questions - as part of the hermeneutic circle (Klein \& Myers, 1999), were: Which roles were required? How did you define an accountability framework? Was this specification of roles and responsibilities necessary? The interviewee also presented us several documents when we could identify figures and narrative concerning the RRS process area - see Leussink (2008).

Table 1: Distribution of interviewees' expertise

\begin{tabular}{l|c|c|c|c}
\hline Field of expertise/B-ITa domain & A & B & C & Total \\
\hline \hline Partnering structure and coordination & 1 & & & 1 \\
IS architecture & 2 & & 2 & 4 \\
Process architecture & 2 & 1 & & 3 \\
Total & 5 & 1 & 2 & 8 \\
\hline Legend: $\mid$ A = Province of Overijssel & & \\
$\mid$ B = Municipality of Enschede & C= Municipality of Zwolle
\end{tabular}

The data analysis was conducted using interpretation (Klein \& Myers, 1999). Having done such analysis by ourselves may also reflect some bias in how we interpreted the data. However, we bear out this decision by the following statements: first, documentation was an important data source in this study. Documents are not simply containers of meanings. They are collectively produced, exchanged, and consumed. They summarize many decisions made by more than one person for a specific purpose. Documents represent specific circumstances including different insights. Therefore, the analysis of documents requires interpretation (Finnegan, 1996). Second, where people are data sources, interpretation also is a suitable analysis technique. Generally, people develop and use their own understanding and observations. Therefore, it was expected that the interviewees attached their own meanings to their answers in the interviews. People interpret their world and we, as observing researchers, interpreted their interpretations.

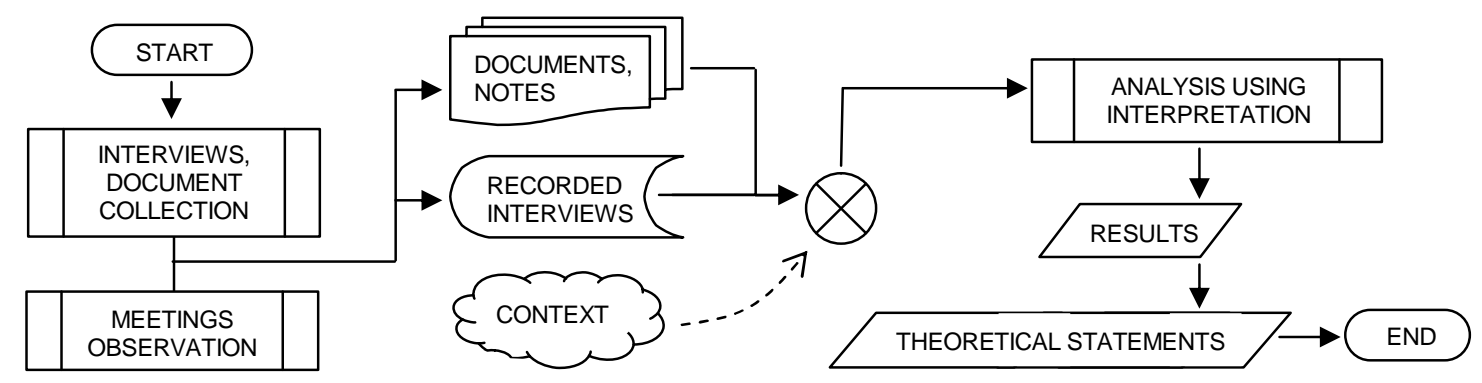

Figure 2: The data analysis process

Figure 2 illustrates the analysis process we followed. The data analysis was conducted using interpretation from a hermeneutic perspective (Klein \& Myers, 1999). We used hermeneutics in the interpretation process because we had multiple data sources. In this case, hermeneutics also helped to obtain results from analyzing the taped interviews, the documentation, the illustrative materials, the meeting observations, and the Overijssel CGP altogether. 


\subsection{Validity threats}

The fact that the gathered data were situation-specific and therefore not easy to replicate, together with the possibility of researcher's bias, were threats to construct validity in this case study. We dealt with these threats by (i) data triangulation in the data collection phase, (ii) using verbatim interview transcripts and notes of observations in order to allow cross checks of particular sources of data, and (iii) checking the observations, and interpretations of them, with participants (member checking) and researchers (peer debriefing).

Furthermore, in order to assure the quality, rigor and trustworthiness of the collected data such that it guaranteed that the results of the research were caused by the phenomena under investigation and not by incidental influences, we addressed internal validity in this case by reflexivity and low inference/rich descriptions.

As the presented case was a single interpretative study - since we studied one (constantly changing) organization, it can be argued that we cannot generalize results. This implies that we face two kinds of external validity threats: (i) single case studies cannot be used to generalize, and (ii) interpretative research cannot generalize. We took some steps to counter them. First, according to Yin (2003), to be able to generalize to valid statements from one case study, we need to use multiple sources of data. This can help to ensure the quality of the final conclusions. Hence, we responded to the first validity threat by using professionals, meetings, documents and illustrative materials as sources of evidence. To confront the second validity concern, we based our analysis process on theories, frameworks, and principles developed by case study research methodologists (e.g., Klein \& Myers, 1999; Lee \& Baskerville, 2003; Walsham, 1995; Yin, 2003). In summary, they claim that the generalization from empirical descriptions to theoretical statements is possible and valid. We therefore abstracted from the data general principles that could throw light on other similar situations (see Section 4).

One can also argue that our results cannot be brought up to the private sector since our case study was conducted in the public sector. Research (e.g., Boyne, 2002; Buelens \& van den Broeck, 2007) analyzing the differences between public and private organizations will support such an argument. However, that research has also found some similarities between the two sectors. Moreover, we have also found evidence, in the case studies we have conducted to design the ICoNOs MM (Santana Tapia et al., 2007; Santana Tapia et al., 2008a; Santana Tapia et al., 2008b), which confirms some similarities. We do believe that CNOs in both sectors begin a BITa project with a solid mission statement that drives the processes to meet the shared goals. This mission reminds the participating organizations of their work principles and respective roles in the network. In those case studies, we have studied entrepreneur-led and governmental CNOs where (i) participants pool costs, skills, and core competences to provide world-class solutions (products or services) that could not be provided by any of them individually; (ii) information systems enable each of the participants to respond dynamically to meet the ever-changing customer needs and to communicate and share information among them; (iii) participants have a clear understanding of the common goal(s) and the functions of each of the participating organizations in order to know what is expected from each of them. Such characteristics are reflected in our definition of CNO (see Section 2). So, we deem appropriate to consider both sectors similar. We acknowledge however that only their purpose could vary. Consequently, this difference in intention creates the context in which they operate and how they operate.

\section{B-ITa Best Practices}

An overview of the case study results is presented in Table 2. Detailed explanation of these results can be found in Santana Tapia \& van Oene (2008). These results indicate the importance of performing processes related to partnering structure, IS architecture, process architecture, and coordination when achieving B-ITa in CNOs. 
Deciding what is "best" is not easy. Best practices can vary over time and from place to place, as new evidence emerge. Moreover, what is "best" also depends on what the CNO wants. In this paper, a best practice is a B-ITa processes that have been justified on the basis of the findings of the Overijssel CGP case study. In the following, we list the identified B-ITa best practices.

Table 2: B-ITa process areas performed in the Overijssel CGP



1. Define a blueprint of how the collaborative networked organization works, describing how different variables of the collaboration fit together as a system to help creating value for each participant (business model definition - BMD - process area).

2. Structure the priorities and allocation of resources and decision rights to create accountability, and to ensure that activities are performed in conformity with policies and procedures (governance structure and compliance - GSC - process area).

3. Create a snapshot of the existing information systems and data, assessing what the current status of the collaborative networked organization is concerning information systems (current IS architecture description - CSA - process area).

4. Create a snapshot of the existing processes analyzing what the current status of the collaborative networked organization, and maintaining a repository of assets and standards (current process architecture description - CPD - process area).

5. Evaluate, select and design processes needed to support the desired to-be state of the process architecture taking into account business and strategy drivers (target process architecture formulation - TPA - process area).

6. Plan, implement, and deploy process improvements based on a thorough understanding of strengths and weaknesses of the collaboration's processes and process assets (organizational process focus planning - PFP - process area).

7. Coordinate the work using direct supervision (DTS process area), communication (informal communication adjustment - InCA - and communication-oriented coordination - COC - process areas), and standardization (STD process area).

As we have conducted our case study in a CGP, we consider these B-ITa best practices to be certainly useful for the public sector. However, they are not clear-cut-limited to this sector. We believe that our results are not specific to CGPs only, but they also apply to the private sector where B-ITa plays a valuable role. Future work will help us to verify such a claim. 


\section{Conclusion}

In this paper, we investigated a Dutch CGP (see Section 3.1) for gathering real-life evidence to support the inclusion of B-ITa process in the domains of the ICoNOs MM, within a specific level.

We make the note that this study is not enough to overcome external validity concerns that a case study is exposed to. For example, the case site investigated was not randomly sampled. Therefore the generalization of findings to a wider population of organizations is limited. However, we can generalize the case study findings to theory and, thus, part of the results can be drawn on by others who work in an organizational context where B-ITa plays a valuable role. The results gained through this study let us (i) to increase our knowledge of the process areas included in the ICoNOs MM, and (ii) to converge on best practices that can be used by CNOs when striving for B-ITa. Future work includes conducting a new case study following a replication logic. Only with replication of findings, such findings could be robust for generalization.

The B-ITa best practices presented in this paper, rather than give prescriptions, can stimulate thinking and action of CNOs in B-ITa projects. These best practices are still open to further empirical confirmation or refutation. Although much more research is required on this topic, we hope that our study contributes to the pool of knowledge in this relevant research stream.

\section{Acknowledgements}

The development of the ICoNOs MM is supported by the Netherlands Organization for Scientific Research (NWO) under contract num. 638.003.407 (Value-Based Business-IT Alignment).

\section{References}

Benbasat, I., Goldstein, D., Mead, M. (1987). The case study research strategy in studies in information systems. MIS Quarterly, Vol 11, No 3, pp. 369-388.

Boyne, G.A. (2002). Public and private management: Whats the difference? Journal of Management Studies, Vol 39, No 1, pp. 97-122.

Buelens, M. \& van den Broeck, H. (2007). An analysis of differences in work motivation between public and private sector organizations. Public Administration Review, Vol 67, No 1, pp. 65-74.

de Koning, D. \& van der Marck, P. (2002). IT Zonder Hoofdpijn: Een Leidraad voor het Verbeteren van de Bedrijfsprestaties. Prentice Hall. In Dutch.

Duffy, J. (2001). Maturity models: Blueprints for e-volution. Strategic and Leadership, Vol 29, No 6, pp. 19-26.

Finnegan, R. (1996). Using documents. In Sapsford, R., Jupp, V., eds.: Data Collection and Analysis. Thousand Oaks, CA: Sage Publications, pp. 138-151.

Klein, H. \& Myers, M. (1999). A set of principles for conducting and evaluating interpretive field studies in information systems. MIS Quarterly, Vol 23, No 1, pp. 67-93.

Lee, A. \& Baskerville, R. (2003). Generalizing generalizability in information systems research. Information Systems Research, Vol 14, No 3, pp. 221-243.

Leussink, M. (2008). Praktijkproeven voorbeeldproject WABO-ICT. In Dutch.

Luftman, J. (2003). Assessing IT-business alignment. Information Systems Management, Vol 20, No 4, pp. 9-15.

Pawson, R. (1996). Theorizing the interview. British Journal of Sociology, Vol 47, No 2, pp. 295-314.

Santana Tapia, R. (2006). A value-based maturity model for IT alignment in networked businesses. In: Proceedings of Workshops and Doctoral Consortium of the $18^{\text {th }}$ Int. Conference on Advanced Information Systems Engineering (CAISE 2006), Luxembourg, Presses Universitaires de Namur, pp. 1201-1208.

Santana Tapia, R., Daneva, M., van Eck, P. (2007). Validating adequacy and suitability of business-IT alignment criteria in an inter-enterprise maturity model. In: Proceedings of the Eleventh IEEE International EDOC Enterprise Computing Conference, Annapolis, MD, USA, IEEE Computer Society Press, pp. 202-213.

Santana Tapia, R. \& van Oene, L. (2008). Some empirical evidence on business-IT alignment processes in the public sector: A case study report. Technical Report TR-CTIT-08-46. University of Twente.

Santana Tapia, R., Daneva, M., van Eck, P., Castro Cárdenas, N., van Oene, L. (2008a). Business-IT alignment domains and principles for networked organizations: A qualitative multiple case study. In: On the Move to Meaningful Internet Services: OTM 2008 Workshops Proc., Monterrey, Mexico, Springer, pp. 241-252. 
Santana Tapia, R., Daneva, M., van Eck, P., Wieringa, R. (2008b). Towards a business-IT alignment maturity model for collaborative networked organizations. In: Proceedings of the International Workshop on Enterprise Interoperability (IWEI 2008), Munich, Germany, CTIT, pp. 70-81.

Santana Tapia, R., van Eck, P., Daneva, M. (2008c). Validating the domains of an inter-organizational business-IT alignment assessment instrument: A case study. Technical Report TR-CTIT-08-53. University of Twente.

Walsham, G. (1995). Interpretative case studies in IS research: Nature and method. European Journal of Information Systems, Vol 4, No 2, pp. 74-81.

Yin, R.K. (2003). Case study research: Design and methods. $3^{\text {rd }}$ edn. Sage Publications. 